\title{
Associations between maternal depressive symptoms, children's behavioral problems and perceptions regarding family interactions
}

\author{
Associações entre sintomas depressivos maternos, problemas \\ comportamentais infantis e percepções \\ sobre as interações familiares
}

\author{
Claudia Mazzer RODRIGUES-PALUCCI ${ }^{1}$ iD 0000-0003-2318-3017 \\ Fernanda Aguiar PIZETA2 ID 0000-0002-9864-1054 \\ Sonia Regina LOUREIRO' ${ }^{1}$ iD) 0000-0001-9423-2897
}

\begin{abstract}
The aim of this study was to verify possible associations between maternal depressive symptoms, children's behavioral problems and perceptions regarding the family interactions, considering the reports of mothers and children. A total of 60 mothers and their school-age children were divided into two equal groups, according to the presence or absence of maternal depression indicators, and evaluated using the following instruments: Sociodemographic Questionnaire, Patient Health Questionnaire-9, Strengths and Difficulties Questionnaire, and scales of family interaction (Escalas de Qualidade nas Interações Familiares). The results indicate that maternal depressive symptoms were associated with children's behavioral problems and with family interactions reported by mothers and children. Maternal depression and positive family interactions reported by the mothers predicted behavioral problems in children. Positive family interactions reported by the mothers also mediated the association between maternal depression and children's behavioral problems, highlighting the relevance of interventions with mothers with depression indicators that have school-age children.
\end{abstract}

Keywords: Child behavior; Depression; Family relations; Mothers.

$\checkmark v \nabla v$

1 Universidade de São Paulo, Faculdade de Medicina de Ribeirão Preto, Programa de Pós-Graduação em Saúde Mental. Av. Tenente Catão Roxo, 2650, Monte Alegre, 14051-140, Ribeirão Preto, SP, Brasil. Correspondence to: S.R. LOUREIRO. E-mail: <srlourei@fmrp.usp.br>.

2 Universidade Paulista, Curso de Psicologia. Ribeirão Preto, SP, Brasil.

Support: Conselho Nacional de Desenvolvimento Científico e Tecnológico (Process no 307945/2018-9) and Fundação de Apoio ao Ensino, Pesquisa e Assistência do Hospital das Clínicas da Faculdade de Medicina de Ribeirão Preto da Universidade de São Paulo.

Article based on the doctoral dissertation of C.M. RODRIGUES-PALUCCI, entitled "Percepções sobre as interações familiares no contexto da depressão materna: preditores de problemas comportamentais e depressão infantil”. Universidade de São Paulo, 2019.

$\boldsymbol{\nabla} \mathbf{\nabla} \boldsymbol{\nabla}$

How to cite this article

Rodrigues-Palucci, C. M., Pizeta, F. A., \& Loureiro, S. R. (2020). Associations between maternal depressive symptoms, children's behavioral problems and perceptions regarding family interactions. Estudos de Psicologia (Campinas), 37, e190048. http://dx.doi. org/10.1590/1982-0275202037e190048 


\section{Resumo}

Objetivou-se verificar as possiveis associações entre os sintomas depressivos maternos, os problemas de comportamento infantil e as percepções sobre as interações familiares, considerando-se os relatos das mães e das crianças. Avaliaram-se 60 mães e seus filhos escolares, divididos, conforme a presença ou ausência de indicadores depressivos maternos, em dois grupos de mesmo tamanho amostral pelos instrumentos Questionário Sociodemográfico, Questionário sobre a Saúde do Paciente-9, Questionário de Capacidades e Dificuldades, e Escalas de Qualidade nas Interações Familiares. Os sintomas depressivos maternos se associaram aos problemas comportamentais infantis e às interações familiares relatadas por mães e crianças. A depressão materna e as interações familiares positivas referidas pelas mães foram preditoras de problemas de comportamento. As interações familiares positivas descritas pelas mães mediaram a associação entre depressão materna e problemas comportamentais infantis, evidenciando a relevância de intervenções voltadas para mães com indicadores de depressão com filhos em idade escolar.

Palavras-chave: Comportamento infantil; Depressão; Relações familiares; Mães.

Depression affects around 322 million people worldwide, with women being more susceptible than men (World Health Organization, 2017) in relation to both diagnostic confirmation and screening for the symptoms (Salk, Hyde, \& Abramson, 2017). Considering the high incidence of depression during the reproductive age of women (Guo, Robakis, Miller, \& Butwick, 2018) and the role of primary caregiver of the children that women exercise in most cultures, maternal depressive symptoms, which include sadness, emptiness or irritable mood as well as somatic and cognitive changes (American Psychiatric Association, 2014), have been recognized as an important risk factor for child development.

Studies have identified the negative impact of maternal depressive symptoms on different childhood outcomes, including internalizing and externalizing behavior problems (Ahun et al., 2018; Van Doorn et al., 2016). This association will be highlighted below, with empirical studies and scientific literature reviews, with emphasis on the influence of family interactions on the behavioral outcomes of school-age children, the focus of the present study.

In the classic meta-analysis of Lovejoy, Graczyk, O'Hare, and Neuman (2000), from the analysis of 46 observational studies, maternal depressive symptoms were found to be associated with more negative family interactions and less positive family interactions. Based on the studies examined, the authors classified interactions expressed as negative affection and hostile or coercive maternal behavior as negatives, and interactions that demonstrated pleasant and enthusiastic actions as positives. It was found that the strength of the associations varied according to parental behaviors studied and the age of the children.

Specifically in relation to school-age children, empirical studies have found that, in the presence of maternal depressive symptoms, inconsistent, poor quality or dysfunctional family interactions were associated with the presence of internalizing and externalizing behavioral problems (Dubois-Comtois, Moss, Cyr, \& Pascuzzo, 2013; Wang, 2018). The more punitive, intrusive and rigid interactions and emotionally mistreatment were associated with internalizing and externalizing problems (Gruhn et al., 2016; Huang, Abura, Theise, \& Nakigudde, 2017; Kuckertz, Mitchell, \& Wiggins, 2018) and family interactions permeated by repeated marital conflicts between the parents were associated with internalizing symptomatology (Najman et al., 2017).

Concerning the designs of the studies about family interactions, it was observed that the majority used observational tasks (Dubois-Comtois et al., 2013; Gruhn et al., 2016; Van Doorn et al., 2016) or the report of a single informant, mainly the mothers (Huang et al., 2017; Kuckertz et al., 2018; Najman et al., 2017; Wang, 2018). Although observational techniques are recognized as the "gold standard" in terms of empirical measures (Smith, 2011), standardized questionnaires are also widely used, especially due to time and cost savings. But also, for the benefits of their use, considering that individuals involved in parent-child relationship can report their interactions in a unique way, whereas an external observer has limited access

2 to the subjective family reality (Hannigan, McAdams, Plomin, \& Eley, 2016). 
Using standardized questionnaires and observational tasks, Van Doorn et al. (2016) studied the mediating effect of family interactions, expressed as maternal affectivity and psychological control, on the association of maternal depressive symptoms with externalizing and internalizing problems in school-age children. Participants were 111 children aged 8-12 years and their mothers, with family interactions being evaluated through observational tasks and the indicators of child behavioral problems through the Child Behavior Checklist answered by the mothers and the Short Mood and Feeling Questionnaire answered by the children. They found that maternal depressive symptoms were associated with less maternal affectivity and that greater psychological control was associated with more externalizing problems, according to the mothers' reports, however, not those of the children. Furthermore, maternal affection and psychological control did not mediate the association with the behavioral problems. The authors emphasized that maternal depression may negatively affect mothers' reports about children's mental health, identifying more problems than children do. It is also possible, according to them, that children with externalizing problems present more difficulty in recognizing, reporting or admitting their symptoms.

Literature data show, therefore, the importance of the use of different informants to comprehend child behavior problems. In a robust meta-analysis study, based on the analysis of 341 studies, De Los Reyes et al. (2015) verified that reports of parents and children, considering child behavior, presented weak to moderate agreement. They identified that the stronger correlations between the parent-child reports were related to externalizing behavioral problems compared to internalizing problems, suggesting greater congruence between reports of more directly observable behaviors.

In the evaluation of family interactions, differences between the reports of parent and child are also common, however, less studied. The meta-analysis of Korelitz and Garber (2016) sought to examine whether disagreements among these informants follow a pattern similar to that found in relation to child behavior. Through the examination of 85 studies, low concordance was found between reports of parents and children, specifically regarding the constructs acceptance, behavioral control and psychological control, indicating that parents and children perceive the family interactions in different ways, not verifying a tendency towards agreement in any of the constructs. However, when analyzing the discrepancies, which refer to the mean differences between the reports, it was found that parents reported higher levels of acceptance compared to the children, and that the children reported higher levels of psychological control than the mothers, suggesting that parents tend to report more favorable interactions than their children do.

Although disagreements between parents and children regarding family interactions are to some extent expected, they may also be related to the presence of maternal mental health problems, especially maternal depression, which is recognized as interfering in the perception of the family functioning and parental practices. In this sense, Pérez, Coo, and Irarrázaval (2018) analyzed the associations between the symptoms of maternal depression and the perceptions of mothers and their children about the family functioning, in terms of family cohesion and adaptation, evaluated by the mothers and children through The Family Adaptability and Cohesion Scales. The authors reported that mothers perceived their families as more cohesive and adapted, compared to their children, however, higher levels of maternal depressive symptoms were associated with lower cohesion and family adaptation reported by both mothers and children.

The study of Daches, Vine, Layendecker, George, and Kovacs (2018) also examined the perceptions of mothers and children with reference to family functioning in the context of maternal depression. The family environment was evaluated by the mothers and children from the 12-item General Functioning Scale of the McMaster Family Assessment Device and the depression of the mothers and children was identified through a diagnostic interview applied by trained physicians. The authors found that in families with maternal depression, mothers and children perceived their family environment to be more dysfunctional, and that family dysfunction reported by the children, but not by the mothers, partially mediated the association between maternal depression and the depressive symptomatology of the children. These findings show the relevance 
of the identification of negative aspects of family interactions, particularly in children's reports, since efforts aimed at improving the family environment can minimize the risk of living with mother's depression.

Considering the studies analyzed, there were consistent associations of maternal depressive symptoms and family interactions, especially those related to mother-child interactions guided by negative parental practices, with negative outcomes for school-age children. However, there was a great diversity of specific variables related to family interactions identified as predictors of children's negatives outcomes and a poor consideration of positive family interactions in this context. Besides that, the studies that used different informants highlighted the importance of the inclusion of children's reports on the family interactions, in order to allow the identification of different perceptions and favor a more accurate and consistent evaluation. Psychogiou and Parry's (2014) had already proposed the need for better elucidation of the mechanisms by which family interactions place the offspring of mothers with depression at risk for more problems. Since the mechanisms may include the quality of family interactions, further studies were required to clarify the way these associations occur.

The present study fits into this gap, aiming to identify the associations between maternal depressive symptoms, children's behavioral problems, and mothers' and children's perceptions about the quality of family interactions, including negative and positive aspects of family relations. The guiding hypotheses adopted were that in the condition of living with maternal depression: (a) family interactions will be more negative and less positive from the perceptions of mothers and children, with the children presenting more behavioral problems, and (b) negative family interactions reported by children, but not by mothers, will mediate the association between maternal depressive symptoms and behavioral problems of the school-age children.

\section{Method}

\section{Participants}

A convenience sample was composed of 60 mother-child dyads, distributed in 2 groups, Group 1 (G1) - with 30 dyads, in which the mothers had current indicators of depression and Group 2 (G2) - with 30 dyads, in which the mothers did not present these indicators, including only one child per family. The indicators of the presence or absence of current depression were evaluated by a screening instrument for depression. The women/mothers were aged between 24 and 50 years $(M=34.8$ years and $S D=6.33)$ and their biological children, were between 9 and 11 years of age $(M=10.56$ years and $S D=0.74$, 30 boys and 30 girls).

It was previously defined that the groups should include at least 30 dyads and be homogeneous regarding the sex of the children. Women with severe chronic illnesses and children with apparent deficiencies and/or serious illnesses, who presented a cognitive level below the average, who had been adopted and/or who did not live with the family of origin, or who lived, or had lived in the last two years with a father or stepfather, were excluded. This last criterion aimed to provide a certain homogeneity concerning the family configurations, in relation to the possibility of the child having lived with two main caregivers.

For the selection of the sample, public elementary schools in a medium-sized city in the state of São Paulo, Brazil were contacted. An invitation letter was sent to mothers by children with the presentation of the study and request for expressions of interest regarding participation. Of the total of 1,442 letters forwarded, 797 were returned, 106 of which showed interest in knowing more about the study and filling in data for later contact. Of these, 32 families did not have suitable times available for participation, did not

4 confirm their interest in participating after further clarification about the study objectives or did not respond 
to the three telephone contact attempts. Of the 74 eligible dyads, 14 were excluded at the time of evaluation, not meeting one of the inclusion criteria. The 60 mother-infant dyads evaluated comprised groups $\mathrm{G} 1$ and $\mathrm{G} 2$.

\section{Instruments}

Sociodemographic characteristics: A general questionnaire was developed to obtain sociodemographic information and data on some specific conditions of the participants and their families. The socio-economic characteristics were assessed using the Critério de Classificação Econômica Brasil (Brazil Economic Classification Criterion) established by the Associação Brasileira de Empresas de Pesquisas (ABEP, Brazilian Association of Research Enterprises).

Indicators of maternal depression: The depressive symptomatology of the mothers was evaluated through the Patient Health Questionnaire-9 (PHQ-9), a screening instrument for depression validated by Spitzer, Kroenke, and Williams (1999) and Kroenke, Spitzer, and Williams (2001) and translated by Pfizer ${ }^{3}$. Total score corresponding to values of 10 or more was adopted as a cut-off point indicating depressive symptomatology. In a study on the psychometric properties of the PHQ-9 performed in Brazil, Osório, Mendes, Crippa, and Loureiro (2009) verified very satisfactory validity. The reliability analysis of this instrument was performed for the present sample $(n=60)$, showing Cronbach's alpha of 0.82 . Data evaluated by the PHQ-9, were used as a criterion for identifying the presence or absence of maternal depressive symptomatology and for the inclusion of the women/mothers in the groups, considering scores higher than 10 for inclusion in G1 and lower for inclusion in G2. As variable of interest in the study, the PHQ-9 score was used as a dichotomous variable for association and regression analysis.

Intellectual performance: The intellectual functioning of the children was evaluated through Raven's Colored Progressive Matrices - Special Scale, which aims to evaluate the non verbal intelligence of children, with Brazilian standardization for public and private school students that was carried out by Angelini, Alves, Custódio, Duarte, and Duarte (1999). Performance corresponding to the 25th percentile or over was one of the inclusion criteria for selection of children in this study.

Perceptions about the quality of the family interactions: The family interactions were evaluated through the Escalas de Qualidade nas Interações Familiares (EQIF, Family Interaction Quality Scales). The instrument was theoretically defined and constructed from validation tests performed by Weber, Prado, and Salvador (2008). It has versions for parents and children, which have questions grouped into nine scales, six with positive aspects of family interactions (involvement, rules and monitoring, positive child communication, positive conjugal climate, parental model and feelings of the child) and three related to aspects considered negative (negative communication, corporal punishment and negative conjugal climate). Weber et al. (2008) and Stasiak, Weber, and Tucunduva (2014) verified good psychometric properties of both versions of the instrument. The scoring of each scale allows the sum of the scores of the positive scales, corresponding to the total positive family interactions, and the scores of the negative scales, representing the total negative family interactions. In the present study, the reliability analysis of this instrument for the present sample showed a Cronbach's alpha of 0.76 in the mothers' evaluation and of 0.64 in the evaluation of the children.

Child behavior: Behavior was evaluated through the parents' version of the Strengths and Difficulties Questionnaire (SDQ), which was developed by Goodman (1997) to track behavioral problems in children and adolescents. Its use is free and it was translated and adapted to Brazil by Fleitlich, Cortázar, and

$\boldsymbol{\nabla} \boldsymbol{\nabla} \boldsymbol{v}$

3 Copyright @ 2005 Pfizer Inc; All rights reserved. Reproduced with permission. 
Goodman (2000). This instrument is composed of one scale of resources and four scales of problems, identifying emotional symptoms, conduct problems, hyperactivity and peers relationship problems. Total score corresponding to values of 16 or more was adopted as a cut-off point indicating behavioral difficulties. Psychometric studies performed by Woerner et al. (2004) and Fleitlich et al. (2000) verified good psychometric qualities. In the reliability analysis for the present study, the problem scales presented a Cronbach's alpha of 0.82 in the evaluation of the mothers.

\section{Procedures}

The present study was appraised and approved by the Research Ethics Committee of the Hospital das Clínicas da Faculdade de Medicina de Ribeirão Preto, Universidade de São Paulo, as case $\mathrm{n}^{\circ}$ 44723015.4.0000.5440. The participation of the mothers and the children was given voluntarily through the signing of the appropriate consent forms. Trained psychologists and psychology students conducted the evaluations with the mothers and children through face-to-face interactions in a single session. The mothers first answered the General Questionnaire, the SDQ, the EQIF, and finally the PHQ-9, with an average duration of 40 minutes. The children initially responded to the Raven, and then to the EQIF, with an average duration of 30 minutes.

\section{Data analysis}

Statistical analysis was performed using the SPSS ${ }^{\circledR} \mid \mathrm{BM}^{\circledR}$ Software (Chicago, USA - version 17), for Windows, adopting a significance level of $5 \%(p \leq 0.05)$. Initially, the Kolmogorov-Smirnov and Shapiro-Wilk tests of normality were performed. Subsequently, descriptive statistics was used.

Comparisons between the groups were performed using the Pearson's chi-square test (categorical variables) and the Mann-Whitney test (continuous variables). For the parametric analysis of comparison of the continuous variables, the effect size was analyzed through Cohen's $d$ from the means and standard deviation, classifying as follow: small (less than 0.2 ), medium (0.2 to 0.5$)$, large (0.5 to 1.0) and very large (above 1.0), according to Maroco (2014).

Spearman's correlation test was applied to identify possible correlations between the following variables: maternal depression, positive and negative family interactions evaluated by the mothers and children, and children's behavior evaluated by the mothers. Significant correlations were classified as: weak ( $r h o=0-0.25$ ), moderate $(r h o=0.26-0.50)$, strong ( $r h o=0.51-0.70$ ) or very strong ( $r h o>0.70)$, according to Maroco (2014). To examine its direct effect, a univariate regression analysis tested the variables maternal depression and children's behavior. In the multivariate regression analysis, the total positive and the total negative family interactions perceived by the mothers and children, as well as the presence of maternal depression, were included as predictor variables.

In the analysis of the mediation model, the influence of maternal depression to children's behavioral problems, mediated by the family interactions as perceived by mothers and children, was evaluated, identifying the direct effect of the depressive symptoms and family interactions for the behavioral problems and the mediation effect via bootstrapping, which consider the Confidence Interval $(\mathrm{Cl})$ at $95 \%$. The explanatory power of the mediation model tested was calculated using the R-squared mediation effect size.

\section{Results}

In the between-groups comparisons, no statistically significant differences were verified between sociodemographic variables. In the total sample, the majority of the mothers reported having studied for 
more than eight years (71.7\%), being engaged in paid activity $(78.3 \%)$ and having one to three children (83.3\%). The children predominantly belonged to two-parent families $(86.7 \%)$ and to classes with better socioeconomics resources $(56.7 \%)$.

Considering the presence or absence of behavioral difficulties of the children reported by mothers, significant statistical differences were found between the groups. Children of G1 presented higher percentages of classifications related to the presence of problems, when compared to those of $\mathrm{G} 2(\mathrm{G} 1=18.27, \mathrm{G} 2=11.20, p=0.013$; Cohen's $d=1.03)$, indicating that mothers with depressive symptoms reported more behavioral problems of their children, when compared to mothers without these indicators.

From the comparisons in relation to the mothers' and children's perceptions about the family interactions, it was verified statistically significant differences between the groups. Mothers of G1, when compared to mothers of $G 2$, reported lower means in the total positive family interactions $(G 1=120.63$, $\mathrm{G} 2=127.80, p=0.012$; Cohen's $d=0.63$ ) and higher means in the total negative family interactions $(\mathrm{G} 1=29.66, \mathrm{G} 2=25.30, p=0.023$; Cohen's $d=0.62)$. Children of $\mathrm{G} 1$, when compared to children of $\mathrm{G} 2$, also reported lower means in the total positive family interactions ( $G 1=121.80, G 2=127.63, p=0.052$; Cohen's $d=0.48$ ) and higher means in the total negative family interactions ( $G 1=26.30, G 2=21.63$, $p=0.041$; Cohen's $d=0.58$ ) (Table 1).

Regarding the correlation analysis, the associations between maternal depression indicators, total positive and total negative family interactions according to mothers' and children's reports, and children's behavioral indicators evaluated by mothers, are presented in Table 2. It was verified that the maternal depression were moderately and negatively associated with total positive family interactions, and positively

Table 1

Comparisons between groups (G1 and G2) regarding the variables children's behavioral problems and family interactions $(n=60)$

\begin{tabular}{|c|c|c|c|c|}
\hline \multirow{2}{*}{ Variables } & \multicolumn{2}{|c|}{$\mathrm{G} 1(n=30)$} & \multicolumn{2}{|c|}{$\mathrm{G} 2(n=30)$} \\
\hline & $M$ & $(S D)$ & $M$ & $(S D)$ \\
\hline Total Behavioral Problems - SDQ & 18.27 & $(8.23)$ & 11.20 & (5.19) \\
\hline Total Positive - EQIF (mothers) & 120.63 & $(12.57)$ & 127.80 & (9.99) \\
\hline Total Negative - EQIF (mothers) & 29.66 & $(7.45)$ & 25.30 & (6.70) \\
\hline Total Positive - EQIF (children) & 121.80 & (13.04) & 127.63 & $(11.10)$ \\
\hline Total Negative - EQIF (children) & 26.30 & $(9.00)$ & 21.63 & (6.84) \\
\hline
\end{tabular}

Note: Mann-Whitney Test. ( ): informants.

EQIF: Family Interaction Quality Scales; M: Mean; SD: Standard Deviation; SDQ: Strengths and Difficulties Questionnaire.

Table 2

Associations between the variables maternal depression, positive and negative family interactions and children's problem behavior, considering the total scores of the instruments $(n=60)$

\begin{tabular}{|c|c|c|c|c|c|}
\hline Variables & 1 & 2 & 3 & 4 & 5 \\
\hline \multicolumn{6}{|l|}{ 1. Maternal depression - PHQ-9 } \\
\hline 2. Total Positive - EQIF (mothers) & $-0.304^{*}$ & & & & \\
\hline 3. Total Negative - EQIF (mothers) & $0.377^{* *}$ & $-0.286^{*}$ & & & \\
\hline 4. Total Positive - EQIF (children) & $-0.302^{*}$ & $0.440^{* *}$ & -0.027 & & \\
\hline 5. Total Negative - EQIF (children) & $0.303^{*}$ & $-0.274^{*}$ & 0.245 & $-0.523^{* *}$ & \\
\hline 6. Total Behavioral Problems - SDQ & $0.447^{* *}$ & $-0.408^{* *}$ & $0.371^{* *}$ & -0.159 & 0.192 \\
\hline
\end{tabular}

Note: Spearman's Nonparametric Correlation. ${ }^{*} p<0.05 ;{ }^{* *} p<0.01 ;()=$ informants.

EQI: Family Interaction Quality Scales; PHQ-9: Patient Health Questionnaire-9; SDQ: Strengths and Difficulties Questionnaire. 
associated with total negative family interactions, according to the reports of mothers and children. A moderate positive association between maternal depression and total behavioral problems, evaluated by the mothers, was also verified. These data suggest that maternal depression was linked to more children's behavioral problems, as perceived by the mothers.

Total positive family interactions reported by mothers presented moderate and positive association to total positive family interactions reported by children. This result indicate that when the mothers reported more positive family interactions, the children also reported them. Total positive family interactions reported by the mothers also showed moderate and negative associations in relation to: total negative family interactions from the children's perception, indicating that when mothers reported more positive interactions, children reported fewer negative interactions; and total behavioral problems, suggesting that mothers that reported more positive family interactions perceived fewer behavioral problems in their children. Regarding the total negative family interactions, reported by mothers, there was a moderate and positive association in relation to total behavioral problems, indicating that when the mothers reported more negative family interactions, they also perceived more total behavioral problems in their children.

Considering the regression analysis presented in Table 3, in the univariate prediction, maternal depression was identified as a significant variable to predict the total behavioral problems in the children. When the total positive and total negative family interactions, from the mothers' perception, were included in the multivariate model, it was identified that maternal depressive symptoms remained a predictor, however, the total score for positive interactions from the maternal perspective was also significant. This indicates that in the presence of maternal depression there were more behavioral problems in the children, but higher scores for positive family interactions equate to fewer difficulties for the children.

In the mediation analyses, the mothers' perceptions of positive family interactions mediated the association between maternal depressive symptoms and total behavioral problems in children, minimizing the negative effect of living with maternal depression. It should be noted, however, that the children's perceptions did not mediate this association. Figure 1 shows the analyses of total negative and total positive family interactions, with the total effect of the depressive symptoms being significant for children's behavior problems $(\beta=7.0667 ; t(58)=1.7762 ; p=0.002 ; 95 \% \mathrm{Cl}=3.5112 ; 10.6221)$ and a predictor for positive family interactions $(\beta=-7.1667 ; t(58)=2.9314 ; p=0.0176 ; 95 \% \mathrm{Cl}=13.0344 ;-1.2989)$. The indirect effect of maternal depressive symptoms in the presence of positive family interactions decreased $(\beta=5.6681$, $t(58)=3.1817, p=0.002,95 \% \mathrm{Cl}=2.1007 ; 9.2355)$, with the mediation effect via bootstrapping considered significant ( $\beta=1.3935 ; 95 \% \mathrm{Cl}=0.2599 ; 3.9550)$, which confirms mediation along this path. The mediation model tested explained about $9 \%$ of the total variance.

\begin{tabular}{|c|c|c|}
\hline Predictor variables & $\beta$ & $95 \% \mathrm{Cl}$ \\
\hline \multicolumn{3}{|l|}{ Univariate model } \\
\hline Maternal depression & $0.463^{* *}$ & $(3.511,10.622)$ \\
\hline \multicolumn{3}{|l|}{ Multivariate model } \\
\hline Maternal depression & $0.324^{* *}$ & $(1.344,8.560)$ \\
\hline Total negative family interactions & 0.201 & $(-0.035,0.456)$ \\
\hline Total positive family interactions & $-0.256^{*}$ & $(-0.320,-0.013)$ \\
\hline
\end{tabular}

Note: ${ }^{*} p<0.05 ;{ }^{* *} p<0.01$

$\mathrm{Cl}$ : Confidence Interval. 


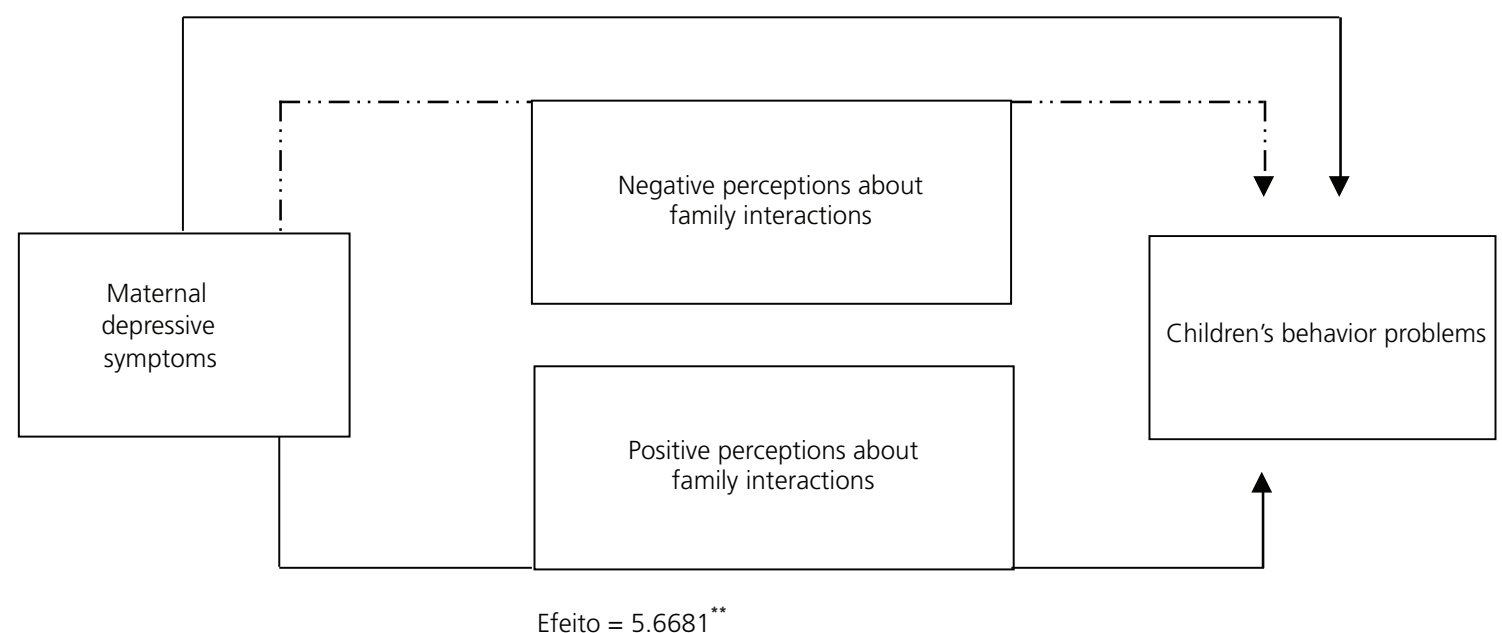

Figure 1. Model of the mediating effect of total posıtıve tamıly interactions, according to mothers' perceptions, for the association between the maternal depressive symptoms and total children's behavioral problems. Black lines indicate significant paths and dashed lines indicate non significant paths.

Note: ${ }^{* *} p<0.01$

\section{Discussion}

One of the hypotheses adopted by this study was that, in the condition of living with maternal depressive symptoms, family interactions would be perceived as more negative and less positive by mothers and children, and that these children would present more behavioral problems. In general, the main findings of the present study confirmed this hypothesis.

It was verified that the mothers with indicators of depression perceived the family interactions as more negative, and less positive, compared to the mothers without indicators of depression. The same was true for the children living with maternal depressive symptoms, compared to the children who did not live with this condition. These findings suggest that in the presence of maternal depression, mothers and children tend to perceive their family interactions in a less favorable way, as evidenced by previous studies (Pérez et al., 2018; Daches et al., 2018) and by the meta-analysis of Lovejoy et al. (2000). In this study, authors analyzed observational studies, reporting that negative family interactions may represent an important factor by which maternal depressive symptoms confer a risk for the presence of more behavioral problems in children.

Considering children's outcomes, the mothers with depressive symptoms perceived more indicators of behavior problems in their children, when compared to the mothers without these symptoms. In this sense, maternal depressive symptoms were associated with more total behavioral problems. This corroborates previous studies that verified the impact of maternal depression on the presence of more internalizing and externalizing symptoms in school-age children (Ahun et al., 2018; Van Doorn et al., 2016).

By examining the direct effects of the family interactions on the child's behavior when living with maternal depression, it was possible to verify that more total negative family interactions, reported by the mothers, was also associated with more total behavioral problems. Thus, based on the mothers' perceptions, negative family interactions seem to put children at risk for the presence of more problems, which is in agreement with previous studies that also evaluated child behavior from the mothers' perspective, however, examined the family interactions through observational tasks (Gruhn et al., 2016; Van Doorn et al., 2016). This finding may be related to the greater propensity of mothers with depression to more negatively assess 
their children's behavior, promoting family relationships expressed by more interactions that are negative. Accordingly, frequent exposure to these interactions can induce feelings of distress and hostility in children (Wang, 2018), which can be perceived as externalizing symptoms by mothers. On the other hand, more total positive family interactions, in mothers' perception, was associated with fewer total behavioral problems, suggesting that positive interactions can have a protective effect in relation to the presence of behavioral difficulties, and can be learned through educational prevention and intervention programs.

Since children tend to report less favorable interactions than their mothers do (Korelitz \& Garber, 2016), we hypothesized that negative family interactions reported by children, but not by mothers, would mediate the association between maternal depressive symptoms and children's behavioral problems. Contrary to expectations, negative family interactions were not identified as predictor or significant mediator of child behavior problems in the context of maternal depression. This non-mediation was also reported by Van Doorn et al. (2016), who hypothesized that this can be explained due to the sample being composed of school-age children, which is a developmental period that can be considered more stable in relation to the family interactions, when compared to the infancy or adolescence phases. This hypothesis can also be applied to the data from the present study, which exclusively addressed school-age children, suggesting that interactional behaviors, especially negative ones, may present a lower impact during moments of greater consolidation as the school age. However, this discussion is only speculative, given the cross-sectional design of the present study and the need of longitudinal studies to test this.

As in the present study, Daches et al. (2018) found no evidence that positive family interactions reported by the children would minimize the effects of the mothers' depression on children's behavior. As discussed by these authors, it can reflect that the children that perceived the family interactions in a more positive way presented a lower risk of behavioral problems, with it being possible that the perception of positive interactions functioned as protection for development.

In this direction, from the regression analyses, it was verified that maternal depression and positive family interactions, perceived by the mothers, were shown to be a significant predictor for the total behavioral problems in children, indicating that in the presence of maternal depression, less positive family interactions pose a risk for more behavioral problems. In the analysis of the interactions, it was found that positive family interactions, perceived by the mothers, mediated the association between maternal depression and total behavioral problems of the children. This indicates a potential resource that could be developed through prevention and intervention programs that contemplate the development of resources for positive interactions between parents and their children, as a way to minimize the negative effect of living with mothers' depression.

The limitations of this study includes the evaluation of the child's behavior through a single informant and the cross-sectional design, which did not allow the detection of the temporal sequence of the influence of maternal depression and family interactions on the child's behavior. Future longitudinal studies, including reporting instruments, with multiple informants such as parents, teachers, and the children themselves, may contribute to a better understanding of the mechanisms by which family interactions place the school-age children of mothers with depression at risk for further behavior problems.

Despite the limitations, considering Psychogiou and Parry's (2014) proposition that multiple mechanisms are involved in the influences of depressive symptomatology on the family interactions, it can be seen that the present study made a breakthrough possible, when comparing the perceptions of mothers and children, regarding their family interactions in the condition of living with maternal depression. This contributes to the expansion of the understanding of the area in relation to aspects to be considered when proposing prevention and intervention programs. The potential protective role of programs aimed at promoting positive family interactions for school-age children living with maternal depression and their implications for maternal and child mental health is highlighted. 


\section{Contributors}

C. M. RODRIGUES-PALUCCI contributed to the designed and executed the study, analyzed the data, wrote the paper and edited the final manuscript. F. A. PIZETA and S. R. LOUREIRO collaborated with the design, assisted with the data analyses and wrote the paper.

\section{References}

Ahun, M. N., Consoli, A., Pingault, J. B., Falissard, B., Battaglia, M., Boivin, M., ... Côté, S. M. (2018). Maternal depression symptoms and internalizing problems in the offspring: the role of maternal and family factors. European Child \& Adolescent Psychiatry, 27(7), 921-932. http://dx.doi.org/10.1007/s00787-017-1096-6

American Psychiatric Association. (2014). Manual Diagnóstico e Estatístico de Transtornos Mentais - DSM-5 (5a ed.). Porto Alegre: Artmed Editora.

Angelini, A. L., Alves, I. C., Custódio, E. M., Duarte, W. F., \& Duarte, J. L. (1999). Manual das matrizes progressivas coloridas de Raven: escala especial. São Paulo: Centro Editor de Testes e Pesquisas em Psicologia.

Daches, S., Vine, V., Layendecker, K. M., George, C. J., \& Kovacs, M. (2018). Family functioning as perceived by parents and young offspring at high and low risk for depression. Journal of Affective Disorders, 226, 355-360. http://dx.doi. org/10.1016/j.jad.2017.09.031

De Los Reyes, A., Augenstein, T. M., Wang, M., Thomas, S. A., Drabick, D. A. G., Burgers, D. E., \& Rabinowitz, J. (2015). The validity of the multi-informant approach to assessing child and adolescent mental health. Psychological Bulletin, 141(4), 858-900. http://dx.doi.org/10.1037/a0038498

Dubois-Comtois, K., Moss, E., Cyr, C., \& Pascuzzo, K. (2013). Behavior problems in middle childhood: the predictive role of maternal distress, child attachment, and mother-child interactions. Journal of Abnormal Child Psychology, 41(8), 1311-1324. http://dx.doi.org/10.1007/s10802-013-9764-6

Fleitlich, B., Cortázar, P. G., \& Goodman, R. (2000). Questionário de Capacidades e Dificuldades (SDQ). Infanto-Revista de Neuropsiquiatria da Infância e da Adolescência, 8(1), 44-50.

Goodman, R. (1997). The Strengths and Difficulties Questionnaire: a research note. Journal of Child Psychology and Psychiatry, 38(5), 581-586. http://dx.doi.org/10.1111/j.1469-7610.1997.tb01545.x

Gruhn, M. A., Dunbar, J. P., Watson, K. H., Reising, M. M., McKee, L., Forehand, R., .. Compas, B. E. (2016). Testing specificity among parents' depressive symptoms, parenting, and child internalizing and externalizing symptoms. Journal of Family Psychology, 30(3), 309-319. http://dx.doi.org/10.1037/fam0000183

Guo, N., Robakis, T., Miller, C., \& Butwick, A. (2018). Prevalence of depression among women of reproductive age in the United States. Obstretics and Gynecology, 131(4), 671-679. http://dx.doi.org/10.1097/AOG.0000000000002535

Hannigan, L. J., McAdams, T. A., Plomin, R., \& Eley, T. C. (2016). Etiological influences on perceptions of parenting: a longitudinal, multi-informant twin study. Journal of Youth and Adolescence, 45, 2387-2405. http://dx.doi.org/10.1007/ s10964-016-0419-0

Huang, K. Y., Abura, G., Theise, R., \& Nakigudde, J. (2017). Parental depression and associations with parenting and children's physical and mental health in a sub-Saharan African setting. Child Psychiatry \& Human Development, 48, 517-527. http://dx.doi.org/10.1007/s10578-016-0679-7

Korelitz, K. E., \& Garber, J. (2016). Congruence of parents' and children's perceptions of parenting: a meta-analysis. Journal of Youth and Adolescence, 45(10), 1973-1995. http://dx.doi.org/10.1007/s10964-016-0524-0

Kroenke, K., Spitzer, R. L., \& Williams, J. B. W. (2001). The PHQ-9: validity of a brief depression severity measure. Journal of General Internal Medicine, 16, 606-613.

Kuckertz, J. M., Mitchell, C., \& Wiggins, J. L. (2018). Parenting mediates the impact of maternal depression on child internalizing symptoms. Depression and Anxiety, 35(1), 89-97. http://dx.doi.org/10.1002/da.22688

Lovejoy, M. C., Graczyk, P. A, O'Hare, E., \& Neuman, G. (2000). Maternal depression and parenting behavior: a meta-analytic review. Clinical Psychology Review, 20(5), 561-592. http://dx.doi.org/10.1016/ S0272-7358(98)00100-7

Marôco, J. (2014). Análise de equações estruturais: fundamentos teóricos, software e aplicações. Pêro Pinheiro: Report Number.

Najman, J. M., Plotnikova, M., Williams, G. M., Alati, R., Mamun, A. A., Scott, J., ... Wray, N. (2017). Maternal depression and family adversity: linked pathways to offspring depression? Journal of Psychiatric Research, 88, 97-104. http:// dx.doi.org/10.1016/j.jpsychires.2017.01.006 
Osório, F. L., Mendes, A. V., Crippa, J. A., \& Loureiro, S. R. (2009). Study of the discriminative validity of the PHQ-9 and PHQ-2 in a sample of Brazilian women in the context of primary health care. Perspectives in Psychiatric Care, 45(3), 216-227. http://dx.doi.org/10.1111/j.1744-6163.2009.00224.x

Pérez, J. C., Coo, S., \& Irarrázaval, M. (2018). Is maternal depression related to mother and adolescent reports of family functioning? Journal of Adolescence, 63, 129-141. http://dx.doi.org/10.1016/j.adolescence.2017.12.013

Psychogiou, L., \& Parry, E. (2014). Why do depressed individuals have difficulties in their parenting role? Psychological Medicine, 44(7), 1345-1347 http://dx.doi.org/10.1017/S0033291713001931

Salk, R. H., Hyde, J. S., \& Abramson, L. Y. (2017). Gender differences in depression in representative national samples: metanalyses of diagnoses and symptoms. Psychological Bulletin, 143, 783-822. http://dx.doi.org/10.1037/bul0000102

Smith, M. (2011). Measures for assessing parenting in research and practice. Child and Adolescent Mental Health, 16(3), 158-166. http://dx.doi.org/10.1111/j.1475-3588.2010.00585.x

Spitzer, R., Kroenke, K., \& Williams, J. (1999). Validation and utility of a self-report version of PRIME-MD: the PHQ Primary Care Study. Journal of the American Medical Association, 282(18), 1737-1744. http://dx.doi.org/10.1001/ jama.282.18.1737

Stasiak, G. R., Weber, L. N. D., \& Tucunduva, C. (2014). Qualidade na interação familiar e estresse parental e suas relações com o autoconceito, habilidades sociais e problemas de comportamento dos filhos. Psico, 45(4), 494-501. http:// dx.doi.org/10.15448/1980-8623.2014.4.15846

Van Doorn, M. M. E. M., Kuijpers, R. C. W. M., Lichtwarck-Aschoff, A., Bodden, D., Jansen, M., \& Granic, I. (2016). Does mother-child interaction mediate the relation between maternal depressive symptoms and children's mental health problems? Journal of Child and Family Studies, 25, 1257-1268, http://doi.org/10.1007/s10826-015-0309-1

Wang, Y. (2018). Intergenerational transmission of depressive symptoms: the role of parental negative perceptions and behaviors. Child Psychiatry \& Human Development, 49(1), 123-136. http://dx.doi.org/10.1007/s10578-017-0734-z

Weber, L. N. D., Prado, P. M., \& Salvador, A. P. V. (2008). Construção e confiabilidade das Escalas de Qualidade na Interação Familiar. Psicologia Argumento, 26, 55-65. Recuperado de https://periodicos.pucpr.br/index.php/psicologiaargumento/ article/ view/20005.

Woerner, W., Fleitlich-Bilyk, B., Martinussen, R., Fletcher, J., Cucchiaro, G., Dalgalarrondo, P., ... Tannock, R. (2004). The Strengths and Difficulties Questionnaire overseas: evaluations e applications of the SDQ beyond Europe. European Child \& Adolescent Psychiatry, 13 (Suppl 2), 47-54. http://dx.doi.org/10.1007/s00787-004-2008-0

World Health Organization. (2017). Depression and other common mental disorders: global health estimates (pp.24). Genebra: Author. Retrieved from https://www.who.int/iris/handle/10665/254610

Received: April 23, 2019

Final version: November 1, 2019

Approved: March 20, 2020 